\title{
How much should we believe correlations between Arctic cyclones and sea ice extent?
}

\author{
Jamie G. L. Rae ${ }^{1}$, Alexander D. Todd ${ }^{1,2}$, Edward W. Blockley ${ }^{1}$, and Jeff K. Ridley ${ }^{1}$ \\ ${ }^{1}$ Met Office, FitzRoy Road, Exeter, EX1 3PB, UK \\ ${ }^{2}$ College of Engineering, Mathematics and Physical Sciences, University of Exeter, Exeter, EX4 4QF, UK
}

Correspondence: Jamie G. L. Rae (jamie.rae@metoffice.gov.uk)

Received: 10 July 2017 - Discussion started: 21 August 2017

Revised: 7 November 2017 - Accepted: 15 November 2017 - Published: 21 December 2017

\begin{abstract}
This paper presents an investigation of the robustness of correlations between characteristics of Arctic summer cyclones and September Arctic sea ice extent. A cyclone identification and tracking algorithm is run for output from 100-year coupled climate model simulations at two resolutions and for 30 years of reanalysis data, using two different tracking variables (mean sea-level pressure, MSLP; and $850 \mathrm{hPa}$ vorticity) for identification of the cyclones. The influence of the tracking variable, the spatial resolution of the model, and spatial and temporal sampling on the correlations is then explored. We conclude that the correlations obtained depend on all of these factors and that care should be taken when interpreting the results of such analyses. Previous studies of this type have used around 30 years of reanalysis and observational data, analysed with a single tracking variable. Our results therefore cast some doubt on the conclusions drawn in those studies.
\end{abstract}

Copyright statement. The works published in this journal are distributed under the Creative Commons Attribution 4.0 License. This license does not affect the Crown copyright work, which is reusable under the Open Government Licence (OGL). The Creative Commons Attribution 4.0 License and the OGL are interoperable and do not conflict with, reduce or limit each other.

(C) Crown copyright 2017

\section{Introduction}

Sea ice is an important part of the climate system due to the key role it plays in the energy balance of the polar regions. In summer its high albedo reduces ocean warming, while in winter its low thermal conductivity acts to insulate the cold atmosphere from the warmer ocean below. In addition, ice melting and growth impacts the ocean temperature through heat exchange, and ocean stratification is affected through salinity changes. Arctic sea ice has undergone substantial changes since satellite-based passive microwave observations first became available nearly four decades ago. Between 1979 and 2012, the annual mean ice extent decreased on average by 3.5 to $4.1 \%$ decade $^{-1}$, while ice extent at the minimum of the annual cycle in September decreased by 9.4 to $13.6 \%$ decade $^{-1}$ over the same period (Vaughan et al., 2013). The Arctic sea ice extent reached record lows in 2007 and 2012. In both years, preconditioning through thinning over several decades had made the ice more susceptible to dramatic reductions (Zhang et al., 2008; Parkinson and Comiso, 2013; Babb et al., 2016).

In addition to the long-term negative trend in September Arctic sea ice extent, there is also considerable interannual variability due to the complex interactions between a variety of physical processes acting on the ice. The September minimum Arctic sea ice extent in any given year will be influenced by seasonal and shorter-term effects, including dynamical and thermodynamic processes in both the atmosphere and the ocean, as well as longer-term trends. Various effects are thought to have contributed to the summer 2007 record minimum, including preconditioning (Zhang et al., 2008); large-scale atmospheric transport of heat into the Arctic (Graversen et al., 2011); anomalous oceanic heat flux 
through the Bering Strait (Woodgate et al., 2010); changes in cloud cover leading to increased surface and basal melting (Kay et al., 2008); and anomalous atmospheric circulation patterns leading to increased ice motion, transpolar drift and ice flux out of the Arctic through the Fram Strait (Zhang et al., 2008).

A low ice extent also occurred in 2012, when the National Snow and Ice Data Center reported that a new record low sea ice extent was reached on 26 August. Prior to this, a strong cyclone had entered the Pacific sector of the Arctic in early August (Simmonds and Rudeva, 2012), where it had an immediate impact on the sea ice. An area of ice in the region of the Chuchki Sea and Bering Strait, measuring about $0.4 \times 10^{6} \mathrm{~km}^{2}$, broke away from the main pack ice. This exposed more of the ocean surface, leading to increased absorption of solar radiation and consequently more ice melt, and also made more of the ice vulnerable to breakup by waves, including those resulting from the storm (Parkinson and Comiso, 2013). However, without preconditioning making the ice more vulnerable to the effects of storms it is unlikely that the 2012 storm would have had the impact it did. Furthermore, the storm was not necessarily crucial to the reaching of a new record minimum: the model study of Zhang et al. (2013) suggested that in the absence of the storm the ice extent would still have reached a new minimum in that year. Storms are therefore not thought to have played a crucial role in the record Arctic sea ice minima of 2007 and 2012.

Nevertheless, cyclones are thought to have a direct impact on the ice (Kriegsmann and Brümmer, 2014). Crawford and Serreze (2016) analysed cyclones in the Modern-Era Retrospective Analysis for Research and Applications (MERRA; Rienecker et al., 2011) and found that the number of cyclones over the central Arctic peaked in summer, with many originating over Siberia. Cyclones will affect cloud cover, which will in turn have an impact on sea ice through changes to radiation and precipitation (e.g. Eastman and Warren, 2010). Meanwhile, the surface winds associated with the cyclone are likely to affect sea ice dynamics (e.g. Ogi et al., 2010), which could cause ice to break up or be advected, leading to exposure of open water and resulting in ocean warming and further melting in summer or freeze-up and additional ice formation in winter. In addition, several recent studies have found apparent connections between cyclones in the Arctic during the summer and sea ice extent in September. Simmonds and Keay (2009) used the University of Melbourne cyclone identification and tracking algorithm (Simmonds et al., 2003) with mean sea-level pressure (MSLP) fields from the JRA-25 atmospheric reanalysis (Onogi et al., 2007) and looked for correlations between the characteristics (number, depth and radius) of cyclones entering the Arctic in September (i.e. at the end of the Arctic sea ice melt season) and the September sea ice extent from the passive microwave data from the National Snow and Ice Data Center over the period 1979-2008. They considered only cyclones passing over ocean or ice points, rather than land. While they found no significant correlations of September ice extent with cyclone number, they did find significant strong negative correlations with cyclone depth and radius, suggesting that deeper, larger cyclones later in the melt season lead to more removal of sea ice.

Screen et al. (2011) used the same algorithm and the MSLP fields from the same atmospheric reanalysis as Simmonds and Keay (2009), with sea ice concentrations from the HadISST dataset (Rayner et al., 2003). For the period 19792009 , they found that, in years in which the ice extent was at least 1 standard deviation less than that of the previous year (which they termed "ice loss years"), there were fewer cyclones in the Arctic in the early part of the melt season (May-July). They suggested various plausible mechanisms for this apparent relationship, including cloud processes, and changes in atmospheric circulation having an impact on ice drift, leading to less removal of ice during the melt season. The result was less robust when the extent was at least 1 standard deviation greater than in the previous year ("ice gain years").

As noted above, Simmonds and Keay (2009) and Screen et al. (2011) both used the same identification and tracking algorithm and the same reanalysis. It is likely that the cyclone track characteristics, such as track density and mean cyclone intensity, found for a given atmospheric dataset will depend on the specific details of the algorithm used (see, e.g. Neu et al., 2013; Rudeva et al., 2014), as well as on the variable used for tracking (for example, $850 \mathrm{hPa}$ vorticity or mean sea-level pressure - see Hodges et al., 2003). On the other hand, Hodges et al. (2003) applied a single algorithm to several different atmospheric reanalyses and found that in the Northern Hemisphere the results were comparable at the synoptic scale but different for smaller-scale features. They also suggested that in some cases the results may depend on the spatial resolution of the reanalysis.

Here, we use a single cyclone identification and tracking algorithm with two different tracking variables to analyse Arctic cyclones for two model simulations and a reanalysis dataset, with the aim of investigating the dependence of cyclone-ice correlations on spatial resolution, tracking variable, and spatial and temporal sampling. In Sect. 2, we give details of the reanalysis, sea ice datasets and model simulations used, as well as the tracking algorithm. We then present our results for the cyclone characteristics and their correlations with sea ice extent in Sect. 3. In Sect. 4, we discuss the results in the context of the sensitivity of cyclone characteristics, and their correlations with sea ice extent, to tracking variable, model resolution, and spatial and temporal sampling. We conclude in Sect. 5 by discussing the implications for studies of cyclone-ice correlations and making some suggestions for future investigations. 


\section{Models, data and methods}

\subsection{Model output}

We use output from the GC2 configuration (Williams et al., 2015) of the HadGEM 3 coupled climate model (Hewitt et al., 2011). This consists of an atmosphere component, the Met Office Unified Model (UM, Cullen and Davies, 1991; Davies et al., 2005); a land-surface component, based on the Joint UK Land Environment Simulator (JULES, Best et al., 2011); an ocean component based on a version of the Nucleus for European Modelling of the Ocean (NEMO, Madec, 2008); and a sea ice component based on a version of the Los Alamos CICE model (Hunke and Lipscomb, 2010). These communicate with each other via the OASIS3 coupler (Valcke, 2013). The GC2 configuration incorporates the Global Atmosphere configuration GA6 (Walters et al., 2017), Global Land configuration GL6 (Walters et al., 2017), Global Ocean configuration GO5 (Megann et al., 2014) and Global Sea Ice configuration GSI6 (Rae et al., 2015).

We use output from simulations at two model resolutions, which we denote by GC2-N96 and GC2-N216. GC2-N96 has an atmospheric horizontal resolution of $1.875^{\circ}$ in longitude and $1.25^{\circ}$ in latitude, while the atmospheric resolution of GC2-N216 is $0.833^{\circ}$ in longitude and $0.556^{\circ}$ in latitude. Both have 85 vertical levels in the atmosphere and use the ORCA025 tripolar grid (which avoids a singularity at the north pole and is nominally of $0.25^{\circ}$ resolution) in the sea ice and ocean components, with 75 vertical levels in the ocean. Both are equilibrium simulations with greenhouse gas and aerosol forcings appropriate for the year 2000, as described by Williams et al. (2015), with the aerosol forcings varying seasonally. The CICE model configuration is based on the zero-layer approximation of Semtner (1976) and has five ice thickness categories, as described by Hewitt et al. (2011) in their Appendix D. For GC2-N96 and GC2-N216, we analyse the last 100 years of a 150-year simulation to avoid transient effects during spin-up.

We perform cyclone tracking with two variables using 6hourly fields of mean sea-level pressure and $850 \mathrm{hPa}$ vorticity from the atmosphere component of the model, with the vorticities being calculated from the $850 \mathrm{hPa}$ wind fields. For the analysis of potential correlations between cyclone characteristics and sea ice, we also use the September monthly mean sea ice extents from the sea ice component.

\subsection{Reanalysis and observations}

With the aim of assessing the cyclones in the climate model simulations against an atmospheric reanalysis, we identify and track cyclones in 6-hourly fields of MSLP and $850 \mathrm{hPa}$ vorticity from the ERA-Interim reanalysis (Dee et al., 2011). While this is also model dependent, it has been shown to compare favourably with observations (see, e.g. Screen and Simmonds, 2011; Lindsay et al., 2014). Again, the vortic- ity fields are calculated from the corresponding winds. We also use sea ice from the HadISST1.2 dataset (Rayner et al., 2003), which is derived from passive microwave satellite observations. For comparison with the sea ice fields calculated by the climate model, we first regrid the HadISST1.2 data from their original $1^{\circ}$ resolution to the climate model ORCA025 grid. However, for the correlations with ERAInterim cyclones we use September ice extents calculated directly from the HadISST ice concentration fields at $1^{\circ}$ resolution. Because the model was run with forcings appropriate for the year 2000, we use ERA-Interim and HadISST data for the period 1990-2009 (i.e. 20 years centred on 2000) for comparison with the model. To calculate the correlations, we then use data for the 30-year period 1982-2011, which is similar (though not identical) to those used by Simmonds and Keay (2009) and Screen et al. (2011).

\subsection{Cyclone identification and tracking algorithm}

We use the TRACK objective cyclone identification and tracking algorithm (Hodges, 1999). The climate model output and reanalysis data are first preprocessed: they are converted to spherical harmonics, a "background field" (all wavenumbers below T5) is removed and they are truncated via the removal of all wavenumbers above a certain threshold. The spherical harmonic fields are then all interpolated onto the same $2.5^{\circ} \times 2.5^{\circ}$ grid; these interpolated fields are used for input into TRACK. The algorithm then identifies and tracks either positive maxima or negative minima in the interpolated, truncated fields. At each $6 \mathrm{~h}$ time point, the algorithm identifies all the maxima or minima above a certain threshold in the field. In the present study, we use thresholds of $10^{-5} \mathrm{~s}^{-1}$ for vorticity and $1 \mathrm{hPa}$ for MSLP. These thresholds are appropriate where smaller spatial scales have been removed by spectral filtering (as in this case) and allow the full life cycle of a cyclone to be captured; they have been used in previous studies (e.g. Hoskins and Hodges, 2002; Bengtsson et al., 2006). The cyclones identified at different time points are then linked together to form tracks. This study focuses on cyclones (as opposed to anticyclones), which correspond to positive maxima in the vorticity anomaly fields or negative minima in the MSLP anomaly fields.

TRACK outputs details of all cyclones with a lifetime of at least 2 days in one hemisphere (in this case the Northern Hemisphere). This work focuses on cyclones passing over non-land points in the Arctic (where the Arctic is defined here as all points north of $65^{\circ} \mathrm{N}$ ). Thus, cyclone tracks satisfying this condition were extracted and all others discarded. For cyclones that originate outside the Arctic, and then pass into the Arctic, or vice versa, or for cyclones which pass over both land and non-land points, only the points on the track over Arctic non-land points were considered. In addition, tracks with a lifetime shorter than 2 days over Arctic non-land points were discarded. 


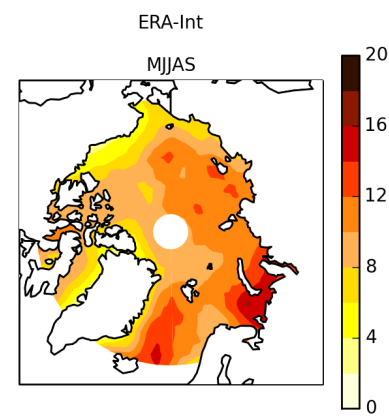

GC2-N216 - ERA-Int

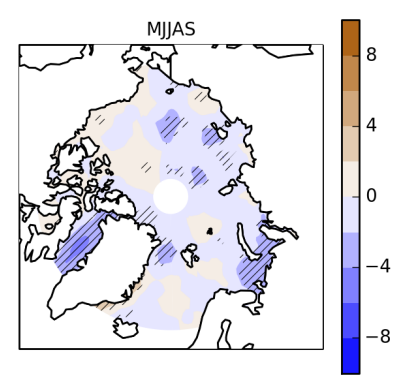

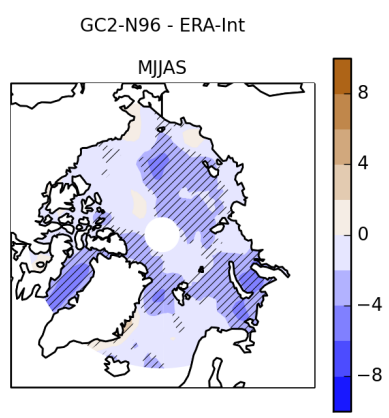

GC2-N216- GC2-N96

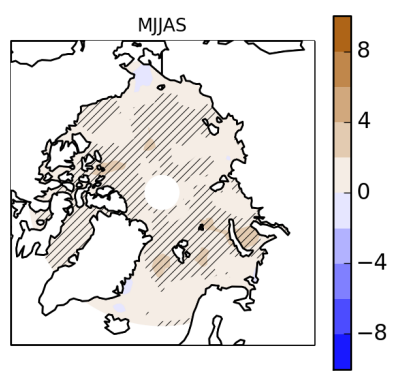

Figure 1. Vorticity-based tracking - multi-annual MJJAS mean cyclone track density $\left(10^{-6} \mathrm{~km}^{-2}\right.$ month $\left.^{-1}\right)$ : ERA-Interim, GC2N96 minus ERA-Interim, GC2-N216 minus ERA-Interim and GC2N216 minus GC2-N96. ERA-Interim uses the 1990-2009 MJJAS mean, while GC2-N96 and GC2-N216 use the MJJAS mean over the last 100 years of the 150-year run. Hatching indicates that the difference is shown by Welch's $t$ test to be statistically significant at the $95 \%$ level.

\subsection{Statistical methods}

To determine the geographical locations where multi-annual mean cyclone characteristics in the two model simulations and in the reanalysis differ significantly from each other, we use Welch's $t$ test, after interpolation to the $2.5^{\circ} \times 2.5^{\circ}$ grid, to test whether the differences in each grid cell are significant at the $95 \%$ level. We also use a Kolmogorov-Smirnov test to compare frequency distributions of Arctic-wide monthly cyclone characteristics and to determine whether they are different at the $95 \%$ confidence level. We then determine Pearson correlation coefficients between the Arctic-wide monthly cyclone characteristics and the September mean ice extent, along with the associated $p$ values. The $p$ value is obtained by permuting the pairs of data used in the correlation calculation many times, recalculating the correlation coefficient in each case. The $p$ value is the probability that the correlation coefficient calculated in this way is greater than or equal to that calculated for the original data. The confidence in the value of the correlation coefficient is then $1-p$.
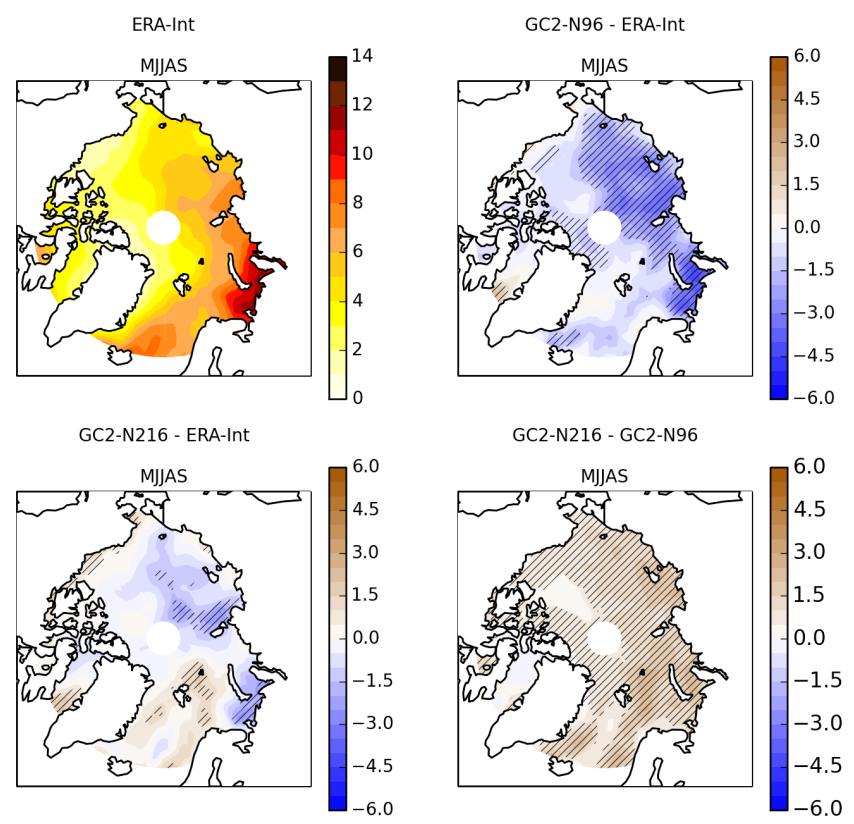

Figure 2. MSLP-based tracking - multi-annual MJJAS mean cyclone track density $\left(10^{-6} \mathrm{~km}^{-2}\right.$ month $\left.^{-1}\right)$ : ERA-Interim, GC2N96 minus ERA-Interim, GC2-N216 minus ERA-Interim and GC2N216 minus GC2-N96. ERA-Interim uses the 1990-2009 MJJAS mean, while GC2-N96 and GC2-N216 use the MJJAS mean over the last 100 years of the 150-year run. Hatching indicates that the difference is shown by Welch's $t$ test to be statistically significant at the $95 \%$ level.

\section{Results}

\subsection{Cyclone characteristics}

We assess cyclones by comparing cyclone characteristics (track count, track density and mean intensity) obtained from TRACK for modelled MSLP and $850 \mathrm{hPa}$ vorticities in GC2N96, GC2-N216 and ERA-Interim. The track count in a particular month is the total number of cyclone tracks in the domain of interest (all non-land points north of $65^{\circ} \mathrm{N}$ ) in that month. The intensity of a cyclone at a given point on its track is taken to be the $850 \mathrm{hPa}$ vorticity or central MSLP (with the background field removed as described in Sect. 2.3). The mean cyclone intensity in a grid box for a given month is the mean intensity of all cyclones in that grid box; the mean intensity for the whole domain is defined similarly. We consider the spatial distributions of multi-annual mean (over the 100 years of GC2 output and 30 years of reanalysis data) track densities and mean intensities (Figs. 1-4), as well as the frequency distributions, over the same period, of wholedomain track count and mean intensity. The frequency distributions for ERA-Interim often cover a narrower range of values than those for GC2, possibly because of the shorter time period of ERA-Interim (see Fig. 5 for an example). 


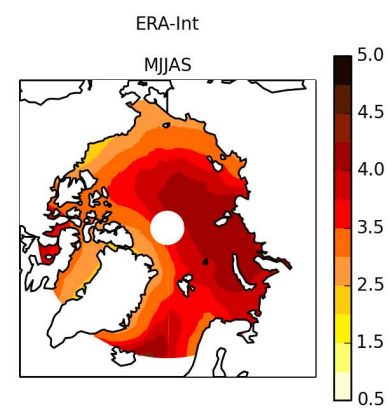

GC2-N216 - ERA-Int
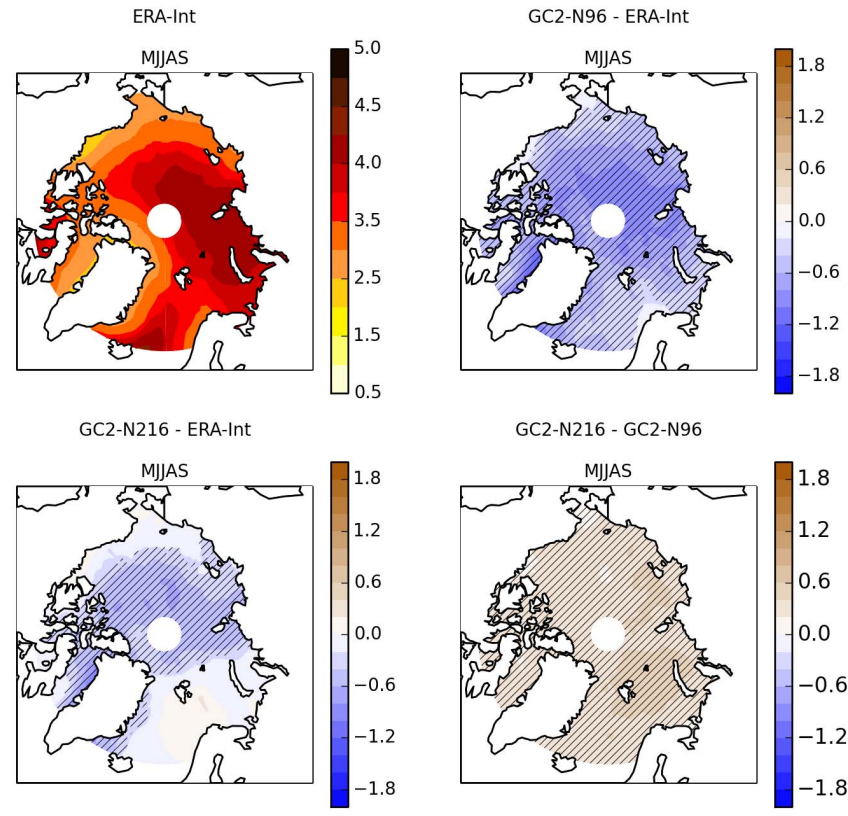

GC2-N216 - GC2-N96

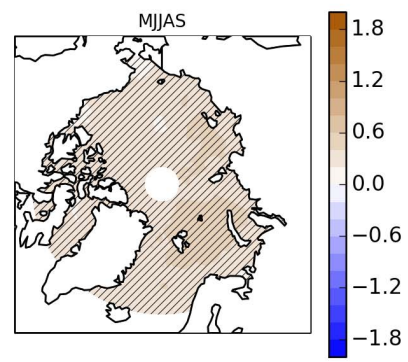

Figure 3. Vorticity-based tracking - multi-annual MJJAS mean cyclone intensity with the background field removed $\left(10^{-5} \mathrm{~s}^{-1}\right)$ : ERA-Interim, GC2-N96 minus ERA-Interim, GC2-N216 minus ERA-Interim and GC2-N216 minus GC2-N96. ERA-Interim uses the 1990-2009 MJJAS mean, while GC2-N96 and GC2-N216 use the MJJAS mean over the last 100 years of the 150 -year run. Hatching indicates that the difference is shown by Welch's $t$ test to be statistically significant at the $95 \%$ level.

The track densities from the vorticity-based analysis (Fig. 1) are generally higher than those from the MSLP-based analysis (Fig. 2), and the cyclones in the latter are mainly restricted to the peripheral seas in the eastern Arctic. The halo seen around Greenland in Fig. 1 occurs because the surface pressure over much of Greenland is lower than $850 \mathrm{hPa}$ (due to the high orography), so there is no $850 \mathrm{hPa}$ vorticity there; we therefore treat the results in this region with caution. Cyclone track densities obtained from both vorticity and MSLP are significantly lower in GC2-N96 than in ERAInterim (Figs. 1 and 2; hatching denotes areas where Welch's $t$ test showed the difference to be significant at the $95 \%$ level). In the case of vorticity, this is the case mainly over the East Siberian and Laptev seas (notably so in June - results for individual months not shown here); we ignore the apparently significant differences in the Davis Strait and Baffin Bay because of the orography-related issues with the $850 \mathrm{hPa}$ vorticity field over Greenland. Differences between GC2-N216 and ERA-Interim are mostly insignificant for both tracking variables - GC2-N216 generally gives a similar representation of cyclone track density to ERA-Interim (except over the East Siberian and Laptev seas in June in the case of vorticity). Consistent with these results, the track density was found to be significantly greater in GC2-N216 than in GC2-N96 in many locations.
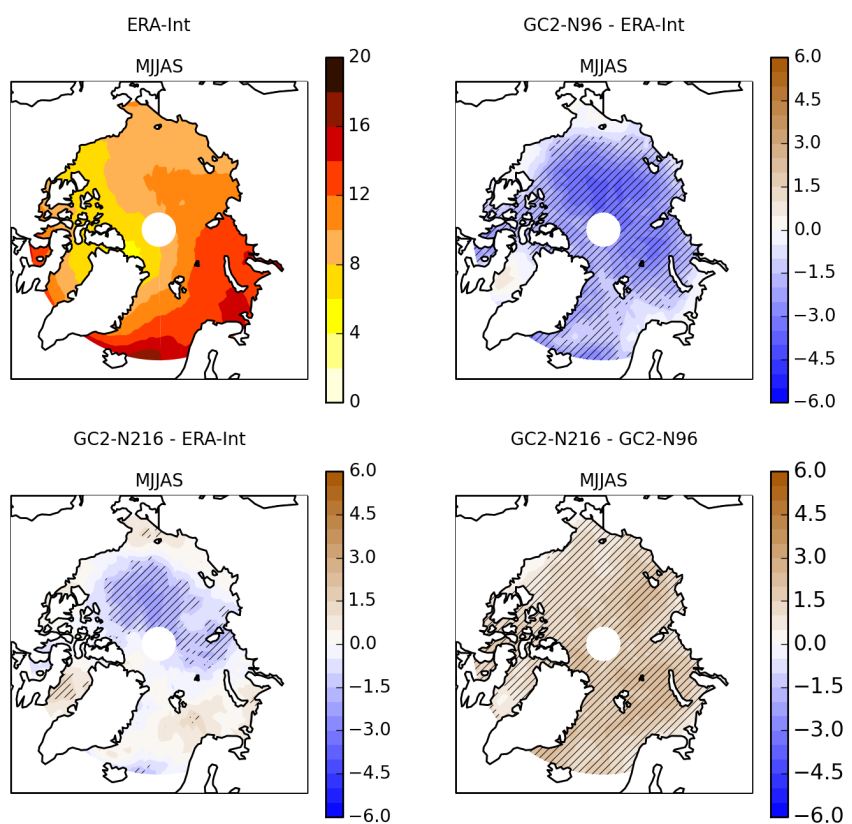

Figure 4. MSLP-based tracking - multi-annual MJJAS mean cyclone intensity with the background field removed (hPa): ERAInterim, GC2-N96 minus ERA-Interim, GC2-N216 minus ERAInterim and GC2-N216 minus GC2-N96. ERA-Interim uses the 1990-2009 MJJAS mean, while GC2-N96 and GC2-N216 use the MJJAS mean over the last 100 years of the 150 -year run. Hatching indicates that the difference is shown by Welch's $t$ test to be statistically significant at the $95 \%$ level.

To explore similarities and differences between the cyclone characteristics obtained for the two tracking variables for ERA-Interim, GC2-N96 and GC2-N216, we use a twosample Kolmogorov-Smirnov test to determine whether the frequency distributions of track counts and intensities from each can be said to be different with at least $95 \%$ confidence. The frequency distributions of whole-domain track count from the vorticity-based and MSLP-based analyses were found to be different (Table 1); this result holds in all months, as well as for both models and the reanalysis. For both tracking variables, the Kolmogorov-Smirnov test suggested that the track count distribution in GC2-N96 differs from that in GC2-N216. The same was true when GC2-N96 and ERA-Interim were compared, except for vorticity-based tracking in August where the possibility that the distributions may be the same could not be rejected. However, we cannot say with $95 \%$ confidence that the track count distributions from GC2-N216 and ERA-Interim are different; this is the case for both tracking variables and is consistent with the results in Figs. 1 and 2, where the differences between ERAInterim and GC2-N216 were seen to be mainly insignificant.

While the vorticity associated with an individual cyclone is related to the MSLP at its centre, there is no simple way to relate Arctic-wide mean MSLP-based and vorticity-based intensities. Additionally, the MSLP-based tracking method 
Table 1. Results of the two-sample Kolmogorov-Smirnov test for comparison of frequency distributions of monthly whole-Arctic cyclone track count and mean cyclone intensity. Results are given for comparison of frequency distributions for vorticity- and MSLP-based tracking for ERA-Interim, GC2-N96 and GC2-N216. For each of the two tracking methods, results are also given for comparison of different pairs of ERA-Interim, GC2-N96 and GC2-N216. Circles (•) denote pairs of distributions which can be said to be different with at least $95 \%$ confidence, while dashes (-) mean the distributions cannot be said to be different at this confidence level. As discussed in the text, it was not possible to compare directly the frequency distributions of mean cyclone intensity from the two tracking methods; hence, these are marked "N/A" here.

\begin{tabular}{|c|c|c|c|c|c|c|c|c|c|}
\hline \multirow[t]{2}{*}{ Month } & \multicolumn{3}{|c|}{ Vorticity vs. MSLP } & \multicolumn{2}{|c|}{ ERA-Int vs. GC2-N96 } & \multicolumn{2}{|c|}{ ERA-Int vs. GC2-N216 } & \multicolumn{2}{|c|}{ GC2-N96 vs. GC2-N216 } \\
\hline & ERA-Int & GC2-N96 & GC2-N216 & Vorticity & MSLP & Vorticity & MSLP & Vorticity & MSLP \\
\hline \multicolumn{10}{|l|}{ Track count } \\
\hline May & $\bullet$ & $\bullet$ & $\bullet$ & $\bullet$ & $\bullet$ & - & - & $\bullet$ & $\bullet$ \\
\hline June & $\bullet$ & - & $\bullet$ & $\bullet$ & $\bullet$ & - & - & $\bullet$ & $\bullet$ \\
\hline July & $\bullet$ & • & $\bullet$ & $\bullet$ & $\bullet$ & - & - & $\bullet$ & $\bullet$ \\
\hline August & $\bullet$ & $\bullet$ & $\bullet$ & - & $\bullet$ & - & - & $\bullet$ & $\bullet$ \\
\hline September & $\bullet$ & $\bullet$ & $\bullet$ & $\bullet$ & $\bullet$ & - & - & $\bullet$ & $\bullet$ \\
\hline \multicolumn{10}{|c|}{ Mean cyclone intensity } \\
\hline May & N/A & N/A & N/A & • & • & - & - & • & • \\
\hline June & N/A & N/A & N/A & $\bullet$ & $\bullet$ & $\bullet$ & - & $\bullet$ & $\bullet$ \\
\hline July & N/A & N/A & N/A & $\bullet$ & $\bullet$ & - & - & $\bullet$ & $\bullet$ \\
\hline August & N/A & N/A & N/A & $\bullet$ & - & $\bullet$ & - & $\bullet$ & - \\
\hline September & N/A & N/A & N/A & $\bullet$ & $\bullet$ & - & - & $\bullet$ & $\bullet$ \\
\hline
\end{tabular}

is biased towards large spatial scales and the vorticity-based method towards smaller scales (Hoskins and Hodges, 2002); the two methods thus tend to identify different systems. It is therefore difficult to compare directly mean intensities from one method with those from the other, and we do not attempt to do so. We can, however, compare the intensities obtained from the three models. The mean cyclone intensities from both tracking variables are significantly less in GC2N96 than in ERA-Interim almost everywhere (Figs. 3 and 4). In the case of vorticity this is true in all months between May and September, while in the case of MSLP the differences are smaller towards the end of the melt season (not shown). For both vorticity and MSLP, the mean intensity in GC2$\mathrm{N} 216$ is also less than in ERA-Interim, but the differences are smaller, and are significant over a smaller area, than in GC2-N96. The mean intensity was found to be significantly greater in GC2-N216 than in GC2-N96 across all non-land points in the Arctic.

The results of the Kolmogorov-Smirnov test for the frequency distributions of mean intensity were similar to those of track count. For both tracking variables, the test suggested that the distributions of mean intensity from GC2-N96 and GC2-N216 are different, as are those from GC2-N96 and ERA-Interim; the exception in both cases is for vorticitybased tracking in August where we cannot reject the possibility that the distributions may be the same. For MSLPbased tracking, we cannot say with $95 \%$ confidence that the mean intensity distributions from GC2-N216 and ERAInterim are different. For vorticity-based tracking, the distributions of mean intensity from GC2-N216 and ERA-Interim were found to be different in June and August; however, in May, July and September we cannot reject the possibility that the distributions may be the same. Thus, the two climate model simulations (GC2-N96 and GC2-N216), identical except for spatial resolution, generate different cyclone characteristics, while two independent models (GC2-N216 and ERA-Interim) with different resolutions can produce similar cyclones.

\subsection{Sea ice}

Before considering the impact of cyclones on Arctic sea ice, it is important that we assess the sea ice extent in the model. In this section, we compare modelled sea ice extent against that from the HadISST1.2 observationally based dataset (Rayner et al., 2003). GC2-N96 reproduces the observed Arctic ice extent well in most months, although GC2N216 performs better in August and September (Fig. 6). At both atmospheric resolutions, the model underestimates September mean sea ice concentration in the Atlantic sector of the Arctic, while there are some regions of overestimation in the Pacific sector, which are more extensive at lower atmospheric resolution (not shown here). There is less ice off the coast of Siberia at higher atmospheric resolution than at lower resolution. These differences were found to be significant at the $95 \%$ level. A more detailed evaluation of the sea ice in GC2-N96 and GC2-N216 was presented by Rae et al. (2015). 


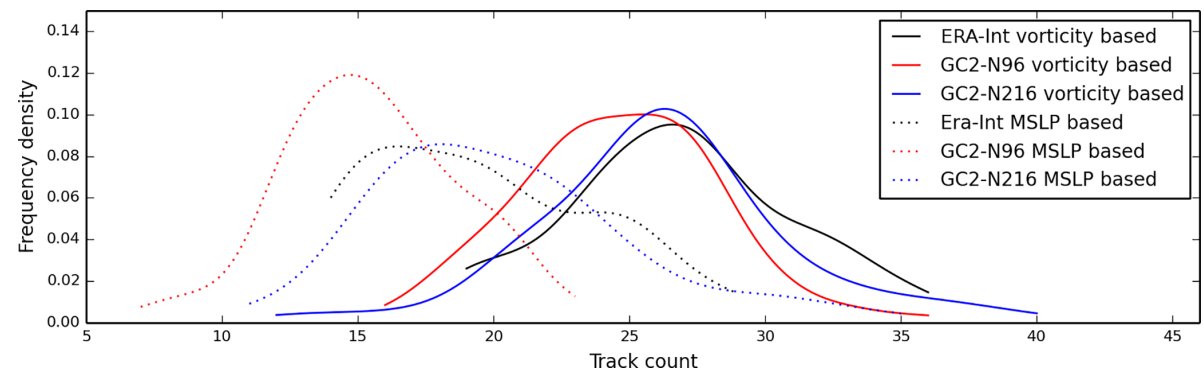

Figure 5. Frequency distributions of August cyclone track count. Use of the MSLP field in the tracking algorithm gives fewer cyclones than use of the vorticity field. The GC2-N216 climate model run is seen to give a similar number of cyclones to the ERA-Interim reanalysis (supported by a two-sample Kolmogorov-Smirnov test), while the lower-resolution GC2-N96 model run gives fewer cyclones.

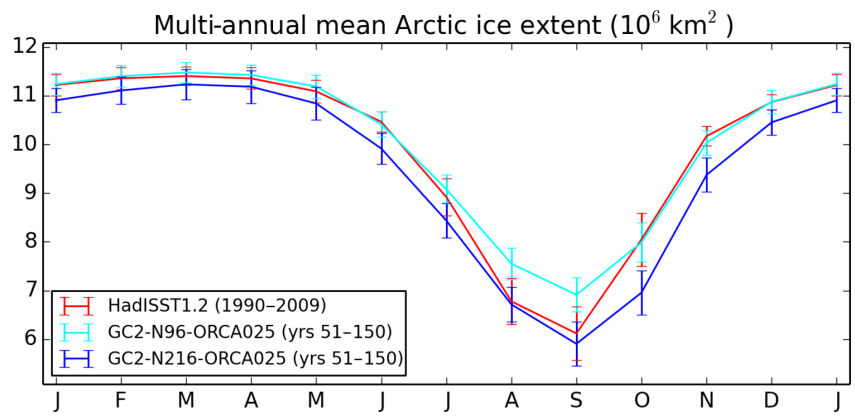

Figure 6. Sea ice extent multi-annual mean seasonal cycles from the HadISST1.2 observational dataset as well as GC2-N96 and GC2N216 climate model runs. Error bars represent standard deviations on the multi-annual means for each month, calculated over the same years as the means themselves. The ice extents in GC2-N216 and HadISST1.2 are seen generally to be within 1 standard deviation of each other.

\subsection{Cyclone-ice correlations}

To explore possible links between cyclones and sea ice, we calculated Pearson correlation coefficients, and the associated $p$ values, between track count in each month between May and September, and September mean Arctic sea ice extent. In Fig. 7, we give the correlation coefficients for GC2N96 and GC2-N216 as well as for ERA-Interim cyclones and HadISST1.2 sea ice. Results are shown only where the confidence level was at least $90 \%$ (i.e. $p \leq 0.1$ ). We found a positive correlation between ERA-Interim vorticity-based track count in the early part of the melt season (May-June) and September mean HadISST1.2 ice extent (suggesting that more cyclones in May-June result in a larger ice extent in September). However, the equivalent correlation for MSLPbased track count was not significant. In addition, in GC2$\mathrm{N} 216$, there was a negative correlation between the June MSLP-based track count and September mean ice extent (linking more cyclones in June with a smaller ice extent in September). Meanwhile, in August, towards the end of the melt season, when cyclones may be expected to play a role in breaking up the ice, and where we may expect to see a

\begin{tabular}{|c|c|c|c|c|c|}
\hline & May & Jun & Jul & Aug & Sep \\
\hline ERA-Int & 0.40 & 0.32 & & & \\
\hline \multicolumn{6}{|l|}{$=\stackrel{0}{ \pm}$ GC2-N96 } \\
\hline \multicolumn{6}{|l|}{ 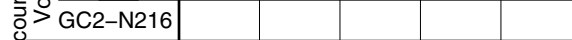 } \\
\hline 总 ERA-Int & & & & 0.33 & \\
\hline \multicolumn{6}{|l|}{ 觇 } \\
\hline GC2-N216 & & -0.21 & & 0.21 & \\
\hline$\nexists \quad$ ERA-Int & & 0.41 & & 0.44 & \\
\hline GC2-N96 & -0.24 & & & & -0.18 \\
\hline \multicolumn{6}{|l|}{$>$ GC2-N216 } \\
\hline$\stackrel{\Phi}{\stackrel{\Phi}{E}}$ a $\quad$ ERA-Int & 0.39 & & & & -0.33 \\
\hline कू GC2-N96 & & & -0.21 & & \\
\hline GC2-N216 & & & & -0.21 & \\
\hline
\end{tabular}

Figure 7. Pearson correlation coefficients between May, June, July, August and September cyclone characteristics (over ocean and ice points only) and September mean sea ice extent. Dark red squares denote positive correlations significant at the $95 \%$ confidence level, light red squares denote positive correlations significant at the $90 \%$ confidence level, dark blue squares denote negative correlations significant at the $95 \%$ confidence level and light blue squares denote negative correlations significant at the $90 \%$ confidence level. Correlation coefficients are not shown where the confidence level is less than $90 \%$.

negative correlation of track count with September ice extent, we found positive correlations in both ERA-InterimHadISST1.2 and GC2-N216 for MSLP-based cyclones.

In the later part of the melt season, we found negative correlations for mean cyclone intensities in September (GC2N96 vorticity-based cyclones and ERA-Interim MSLP-based cyclones), in August (GC2-N216 MSLP-based cyclones) and in July (GC2-N96 MSLP-based cyclones). However, we also found a strong and significant positive correlation between August mean ERA-Interim vorticity-based intensity and September HadISST1.2 ice extent. Earlier in the melt season, there is a positive correlation found between ERA-Interim MSLP-based intensity in May and September HadISST1.2 ice extent and a similar positive correlation for the ERA-Interim vorticity-based intensity in June. However, in GC2-N96 there is a correlation of the opposite sign 


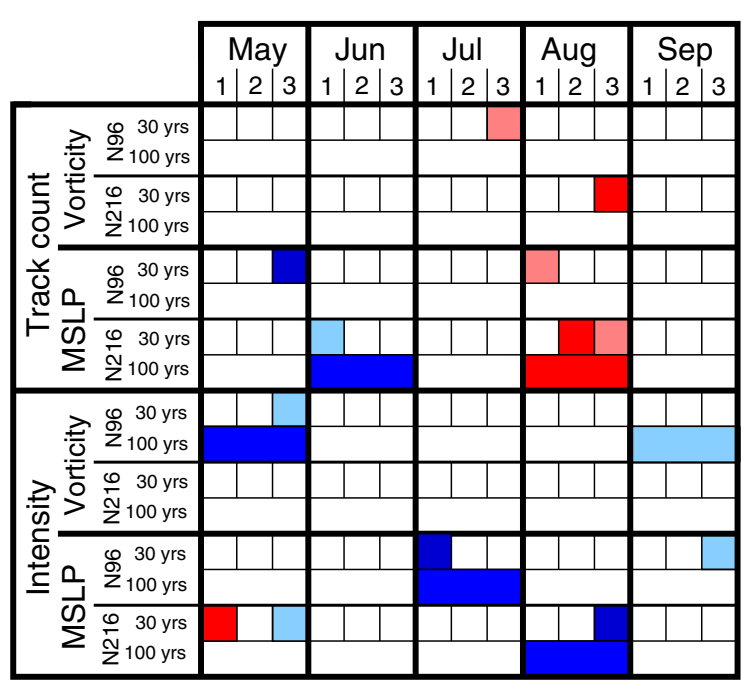

Figure 8. Impact of temporal sampling, demonstrated by correlations over the 100-year period and different, discontinuous, 30-year subsets of output from GC2-N96 and GC2-N216 runs. Colours denote sign of, and confidence in, Pearson correlation coefficients between May, June, July, August and September cyclone characteristics (over Arctic non-land points) and September mean sea ice extent. Dark red squares denote positive correlations significant at the $95 \%$ confidence level, light red squares denote positive correlations significant at the $90 \%$ confidence level, dark blue squares denote negative correlations significant at the $95 \%$ confidence level and light blue squares denote negative correlations significant at the $90 \%$ confidence level. White squares indicate correlation is not significant at $90 \%$ confidence or higher. Columns marked " 1 ": first 30 years of the 100-year period. Columns marked " 2 ": middle 30 years of the 100 -year period. Columns marked " 3 ": last 30 years of the 100-year period.

(i.e. negative) between May vorticity-based intensity and September mean ice extent.

\section{Discussion}

\subsection{Consideration of cyclone-ice correlations in the context of previous studies}

While some of the correlations we found between cyclone characteristics and September ice extent are consistent with results published by other authors (Simmonds and Keay, 2009; Screen et al., 2011), there are others that cannot be explained in relation to those studies. In addition, in some cases where based on previous work one would expect to see correlations, no such significant correlations were found or the correlations had the opposite sign to that expected. For example, the lack of correlation between ERA-Interim MSLP-based track count in the early part of the melt season and September mean HadISST1.2 ice extent contradicts the results of Screen et al. (2011), despite the strong, positive correlation seen for the equivalent vorticity-based track count. The negative correlations seen in some cases between cyclone intensity later in the melt season (in July, August and September) and September ice extent are consistent with the results of Simmonds and Keay (2009), who found a strong and significant correlation between mean cyclone depth in September and mean September ice extent, where they defined cyclone depth as the pressure difference between the centre and edge of the cyclone. This is contradicted by the positive correlation seen for August mean intensity in ERAInterim. Additionally, the negative correlation between May vorticity-based intensity and September mean ice extent in GC2-N96 tends to contradict the results of Screen et al. (2011). On the other hand, the positive correlation found between ERA-Interim MSLP-based intensity in May and September HadISST1.2 ice extent could be consistent with the findings of Screen et al. (2011), although their focus was on track count rather than cyclone intensity. In the rest of this section, we attempt to explain these findings, and our results in general, by considering the impact of differences in the model simulation, choice of tracking variable, and spatial and temporal sampling on the correlations obtained.

\subsection{Dependence on model and resolution}

For a given tracking variable (vorticity or MSLP), we saw wide variations in cyclone-ice correlations between the models. The track densities and mean intensities in GC2-N216 are significantly higher than those in GC2-N96, suggesting that these are strongly resolution dependent, as the model setups for those simulations were identical apart from the resolution. These differences in cyclone characteristics may lead to differences in the interactions between cyclones and sea ice and thus to the different correlations that we saw in those simulations. Meanwhile, despite the cyclone characteristics in GC2-N216 being similar to those in ERA-Interim, the correlations with September ice extent are different. This is likely to be because outputs are from different models: the ERA-Interim data are from an atmosphere, surface and wave model that assimilates observations (Dee et al., 2011), whereas GC2-N216 is a fully coupled climate model without data assimilation. In addition, ERA-Interim and HadISST1.2 include the effects of climate change, whereas GC2-N96 and GC2-N216 are equilibrium climate model runs. It is thus likely that other factors are having an influence. Model resolution, and other model properties, can therefore play a potentially crucial role in determining the correlations seen.

As mentioned in Sect. 2.3, the mean cyclone intensities presented in Fig. 3 have had the background field (wavenumbers $<5$ ) removed and can thus be thought of as anomalies. To evaluate the effect of the removal of the background field, we also plotted maps of absolute intensity (not shown here). For the vorticity-based analysis, the intensity obtained from the ERA-Interim data was intermediate between those from GC2-N96 and GC2-N216, suggesting that resolution may be more important when absolute values are considered (the 
$1^{\circ}$ resolution of ERA-Interim is intermediate between those of the other two simulations). In the MSLP-based analysis, however, the absolute intensities from ERA-Interim do not lie between those of the two GC2 simulations, implying that the situation is more complicated than simple dependence on resolution. The differences between geographical distributions of absolute intensities and intensity anomalies, and their dependence on resolution and tracking variable, is also reflected in differences in cyclone-ice correlation depending on whether absolute values or anomalies are used. We have presented correlations only for intensity anomalies, as we believe the departure of the intensity from the background field to be a more meaningful predictor of the possible impact of the cyclone on the sea ice.

\subsection{Dependence on tracking algorithm and variable}

A number of differences were seen between the cycloneice correlations for vorticity-based and MSLP-based track counts. For example, we found a positive correlation between HadISST September ice extent and track count early in the melt season (May and June) for vorticity-based cyclones in ERA-Interim, but no similar correlation with the MSLPbased track count. This is in contrast to Screen et al. (2011), who used MSLP from the JRA-25 reanalysis as their tracking variable and found apparent links between early-melt-season track count and September ice extent. However, in addition to a different reanalysis dataset, Screen et al. (2011) used the University of Melbourne cyclone finding and tracking algorithm (Simmonds et al., 2003), rather than the TRACK algorithm (Hodges, 1999) applied here. Neu et al. (2013) applied several different tracking algorithms to the same atmospheric reanalysis and examined a variety of cyclone characteristics, including track count and cyclone intensity. They found wide variations in track count between the algorithms, depending on such factors as the threshold for detection, the minimum distance between two cyclones and whether the input data were preprocessed by smoothing (which has the same effect as reducing the resolution, leading to fewer cyclones being detected). These variations have in some previous studies been found to be substantial enough that two different algorithms give opposite signs for the trends in cyclone characteristics in particular regions under climate change (Raible et al., 2008). Thus, the lack of consistency with the results of Screen et al. (2011) may not be surprising, and this provides a good illustration of the potential for different algorithms to give different results.

In the present study, tracking performed on the MSLP field yielded fewer cyclone tracks than that on the vorticity field, although the dependence on resolution was similar for both variables. Some of the algorithms in the study of Neu et al. (2013) used vorticity as the tracking variable, some used MSLP and some used a combination of the two, while others used other variables, such as $850 \mathrm{hPa}$ geopotential height. Neu et al. (2013) did not draw conclusions about the impact of the tracking variable on cyclone characteristics; they emphasised the difficulty of attributing differences in cyclone characteristics to specific aspects of the algorithms, due to multiple differences between the algorithms, which are likely to combine non-linearly. Rudeva et al. (2014) did investigate sensitivity of cyclone characteristics to particular aspects of the algorithms, but not to the variable used. However, Hodges et al. (2003) used the identification and tracking algorithm of Hodges (1999) to analyse cyclone tracks in several reanalysis datasets using both vorticity and MSLP as tracking variables. As in the present study, they detected fewer cyclones with MSLP than with vorticity, which they attributed to the fact that MSLP-based analyses tend to pick up larger-scale features than vorticity-based analyses, leading to fewer detections in regions where smaller-scale features dominate. In addition, we found that MSLP-based cyclones were concentrated in the eastern Arctic to a greater extent than vorticitybased cyclones (compare Figs. 1 and 2), which is also consistent with the results found by Hodges et al. (2003) for winter (see their Fig. 1). Given these differences in the number of cyclone tracks and their geographical distribution between the two tracking variables, it is perhaps not surprising that we also see such differences in the correlations with September ice extent. This underlines the possibility for the same algorithm to give different results depending on the variable used.

There are also differences in the intensity-ice correlations for the two tracking variables. There is a negative correlation between MSLP-based mean intensity from ERA-Interim late in the melt season (September) and HadISST1.2 September ice extent, consistent with Simmonds and Keay (2009), but no such correlation for the vorticity-based intensity. We also found negative correlations between September ice extent and MSLP-based cyclone intensity in August for GC2N216 and in July for GC2-N96 as well as between September ice extent and vorticity-based intensity in GC2-N96 in May and September. However, for the reasons given in Section 3.1 we were unable to compare directly the mean intensities from the two methods.

\subsection{Impact of domain choice}

In the preceding analysis, we followed Simmonds and Keay (2009) in considering only cyclones passing over non-land points north of $65^{\circ} \mathrm{N}$. However, other authors (e.g. Screen et al., 2011) have included all points (land, ocean and ice) in that region. We therefore examined the impact of this spatial sampling by recalculating the correlations, between September ice extent and cyclone characteristics in preceding months, using all cyclones north of $65^{\circ} \mathrm{N}$ (not shown here). Some correlations are significant in both domains. For example, for the ERA-Interim data, the correlations for the track count from the vorticity-based analysis in May and the intensities from the MSLP-based analysis in May and the vorticity-based analysis in June are strong and significant for 
both domains. Similarly, for GC2-N96, the correlations for vorticity-based intensities in May and September and MSLPbased intensity in July are significant in both domains. Finally, for GC2-N216, the correlations for track count and intensity in August are significant in both domains. However, other correlations were found to be significant in only one of the domains, suggesting that the results are at least partly domain dependent.

\subsection{Impact of temporal sampling}

In the preceding analysis, we used 30 years of data for ERAInterim-HadISST1.2 but 100 years for GC2-N96 and GC2N216. We now investigate the effect of shorter temporal sampling by calculating the correlations, over non-land points north of $65^{\circ} \mathrm{N}$, for different, discontinuous, 30-year periods (the first, middle and last 30 years) within the 100 years of GC2-N96 and GC2-N216 output. Figure 8 shows these and compares them with the correlations over the whole 100 years. None of the correlations are significant at the $90 \%$ level in all of the 30-year periods. Most of the correlations that are significant at either 90 or $95 \%$ confidence over the full 100-year period are significant in only one of the 30-year subsets; meanwhile, some significant correlations seen in one of the 30-year periods are found not to be significant over the whole 100 years. The correlation for vorticity-based mean intensity in September in GC2-N96, found to be significant at the $90 \%$ level over the whole 100 years, is not significant in any of the 30-year subsets. For GC2-N96, significant positive correlations of August track count with September ice extent were found for two of the 30-year periods (95\% confidence in the second and $90 \%$ in the third) and for the whole 100 -year period ( $95 \%$ confidence).

The potential for identification of spurious correlations is illustrated by the May intensity from the MSLP-based analysis of GC2-N216 model output. In this case, the correlation with September sea ice extent was positive in the first 30 -year period (95\% confidence) and negative in the third (90\% confidence), while over the whole 100 years there was no correlation significant at $90 \%$ confidence or above. Thus, different, discontinuous, 30-year periods of a 100-year time series can produce a significant positive correlation, a significant negative correlation or no significant correlation at all, highlighting the dependence of the results on temporal sampling.

Studies using reanalyses for cyclone tracking and satellitebased observations for sea ice concentration are necessarily limited to the period since 1979 due to the availability of satellite data. So, for example, Simmonds and Keay (2009) therefore considered the period 1979-2008, Screen et al. (2011) considered 1979-2009 and we have considered 1982-2011 in our analysis of the ERA-Interim data in the present paper. However, the results presented here suggest that the correlations obtained in such analyses may be dependent on the period selected.

\section{Summary and conclusions}

We have used a single cyclone identification and tracking algorithm with two different tracking variables $(850 \mathrm{hPa}$ vorticity and MSLP) and three model simulations (ERA-Interim reanalysis and two simulations with the same climate model at different atmospheric resolutions) to study the number of cyclones in the Arctic during the summer sea ice melt season and their mean intensity. We also studied the correlations between these cyclone characteristics and the September mean Arctic sea ice extent. We found some correlations between September sea ice extent and cyclone characteristics that are consistent with previous studies and others that are not.

Crucially, the correlations were found to be dependent on various aspects of the model, such as resolution, as well as on the variable used for tracking, and on spatial and temporal sampling. One key result for the correlation between MSLP-based mean cyclone intensity in May and sea ice extent in September showed significant positive and negative correlations for discontinuous 30-year subsets of the same 100 years of output from a particular model simulation, while over the full 100 years the correlation was not significant. For this reason, we suggest that caution should be exercised when performing studies such as this, especially where data are only available for a limited period. Previous studies published in the literature, which were limited to approximately 30 years for which satellite observations of sea ice extent were available, and which used only one tracking variable and one resolution, may therefore have drawn unreliable conclusions from a limited set of results. The interaction between cyclones and sea ice is clearly complicated, involving many competing physical processes, and further investigations, focused on developing a better understanding of these processes, would be beneficial.

Code and data availability. For details on how to obtain the code for the GC2 configuration of HadGEM3, please see Williams et al. (2015). Details of the TRACK algorithm and how to obtain it can be found at http://www.nerc-essc.ac.uk/ kih/TRACK/Track.html (Hodges, 2017). Information about the ERA-Interim reanalysis dataset and how to obtain it is given by Dee et al. (2011). The HadISST sea ice data are freely available; please see Rayner et al. (2003) or Titchner and Rayner (2014) for details.

Competing interests. The authors declare that they have no conflict of interest.

Acknowledgements. We are grateful to Kevin Hodges of the Department of Meteorology, University of Reading, and Ruth McDonald and Claudio Sanchez of the Met Office for advice and assistance on running the TRACK algorithm. We thank the anonymous reviewers for their comments, which have led to improvements in the presentation and explanation of the results 
and their implications. This work was supported by the Joint UK BEIS-Defra Met Office Hadley Centre Climate Programme (GA01101).

Edited by: Jean-Louis Tison

Reviewed by: two anonymous referees

\section{References}

Babb, D. G., Galley, R. J., Barber, D. G., and Rysgaard, S.: Physical processes contributing to an ice free Beaufort Sea during September 2012, J. Geophys. Res.-Oceans, 121, 267-283, https://doi.org/10.1002/2015JC010756, 2016.

Bengtsson, L., Hodges, K. I., and Roeckner, E.: Storm Tracks and Climate Change, J. Climate, 19, 3518-3543, https://doi.org/10.1175/JCLI3815.1, 2006.

Best, M. J., Pryor, M., Clark, D. B., Rooney, G. G., Essery, R. L. H., Ménard, C. B., Edwards, J. M., Hendry, M. A., Porson, A., Gedney, N., Mercado, L. M., Sitch, S., Blyth, E., Boucher, O., Cox, P. M., Grimmond, C. S. B., and Harding, R. J.: The Joint UK Land Environment Simulator (JULES), model description Part 1: Energy and water fluxes, Geosci. Model Dev., 4, 677-699, https://doi.org/10.5194/gmd-4-677-2011, 2011.

Crawford, A. D. and Serreze, M. C.: Does the Summer Arctic Frontal Zone Influence Arctic Ocean Cyclone Activity?, J. Climate, 29, 4977-4993, https://doi.org/10.1175/JCLI-D-150755.1, 2016.

Cullen, M. J. P. and Davies, T.: A conservative split-explicit integration scheme with fourth-order horizontal advection, Q. J. Roy. Meteorol. Soc., 117, 993-1002, 1991.

Davies, T., Cullen, M. J. P., Malcolm, A. J., Mawson, M. H., Staniforth, A., White, A. A., and Wood, N.: A new dynamical core for the Met Office's global and regional modelling of the atmosphere, Q. J. Roy. Meteorol. Soc., 131, 1759-1782, 2005.

Dee, D. P., Uppala, S. M., Simmons, A. J., Berrisford, P., Poli, P., Kobayashi, S., Andrae, U., Balmaseda, M. A., Balsamo, G., Bauer, P., Bechtold, P., Beljaars, A. C. M., van de Berg, I., Biblot, J., Bormann, N., Delsol, C., Dragani, R., Fuentes, M., Greer, A. J., Haimberger, L., Healy, S. B., Hersbach, H., Holm, E. V., Isaksen, L., Kallberg, P., Kohler, M., Matricardi, M., McNally, A. P., Mong-Sanz, B. M., Morcette, J.-J., Park, B.-K., Peubey, C., de Rosnay, P., Tavolato, C., Thepaut, J. N., and Vitart, F.: The ERAInterim reanalysis: Configuration and performance of the data assimilation system, Q. J. Roy. Meteorol. Soc., 137, 553-597, https://doi.org/10.1002/qj.828, 2011.

Eastman, R. and Warren, S. G.: Interannual variations of Arctic cloud types in relation to sea ice, J. Climate, 23, 4216-4232, https://doi.org/10.1175/2010JCLI3492.1, 2010.

Graversen, R. G., Mauritsen, T., Drijfhout, S., Tjernstrom, M., and Martensson, S.: Warm winds from the Pacific caused extensive Arctic sea-ice melt in summer 2007, Clim. Dynam., 36, 21032112, https://doi.org/10.1007/s00382-010-0809-z, 2011.

Hewitt, H. T., Copsey, D., Culverwell, I. D., Harris, C. M., Hill, R. S. R., Keen, A. B., McLaren, A. J., and Hunke, E. C.: Design and implementation of the infrastructure of HadGEM3: the next-generation Met Office climate modelling system, Geosci. Model Dev., 4, 223-253, https://doi.org/10.5194/gmd-4-2232011, 2011.
Hodges, K. I.: Adaptive constraints for feature tracking, Mon. Weather Rev., 127, 1362-1373, 1999.

Hodges, K.: TRACK 1.4.0, Universtity of Reading, available at: http://www.nerc-essc.ac.uk/ kih/TRACK/Track.html, last access: 18 December 2017.

Hodges, K. I., Hoskins, B. J., Boyle, J., and Thorncroft, C.: A Comparison of Recent Reanalysis Datasets Using Objective Feature Tracking: Storm Tracks and Tropical Easterly Waves, Mon. Weather Rev., 131, 2012-2037, 2003.

Hoskins, B. J. and Hodges, K. I.: New perspectives on the Northern Hemisphere winter storm tracks, J. Atmos. Sci., 59, 1041-1061, 2002.

Hunke, E. C. and Lipscomb, W. H.: CICE: the Los Alamos sea ice model documentation and software users' manual, Version 4.1, LA-CC-06-012, Los Alamos National Laboratory, NM, 2010.

Kay, J. E., L'Ecuyer, T., Gettelman, A., Stephens, G., and O’Dell, C.: The contribution of cloud and radiation anomalies to the 2007 Arctic sea ice extent minimum, Geophys. Res. Lett., 35, L08503, https://doi.org/10.1029/2008GL033451, 2008.

Kriegsmann, A. and Brümmer, B.: Cyclone impact on sea ice in the central Arctic Ocean: a statistical study, The Cryosphere, 8 , 303-317, https://doi.org/10.5194/tc-8-303-2014, 2014.

Lindsay, R., Wensnahan, M., Schweiger, A., and Zhang, J.: Evaluation of Seven Different Atmospheric Reanalysis Products in the Arctic, J. Climate, 27, 2588-2606, https://doi.org/10.1175/JCLID-13-00014.1, 2014.

Madec, G.: NEMO ocean engine, Tech. Rep. 27, Note du Pole de modélisation, Institut Pierre-Simon Laplace (IPSL), 2008.

Megann, A., Storkey, D., Aksenov, Y., Alderson, S., Calvert, D., Graham, T., Hyder, P., Siddorn, J., and Sinha, B.: GO5.0: the joint NERC-Met Office NEMO global ocean model for use in coupled and forced applications, Geosci. Model Dev., 7, 10691092, https://doi.org/10.5194/gmd-7-1069-2014, 2014.

Neu, U., Akperov, M. G., Bellenbaum, N., Benestad, R., Blender, R., Caballero, R., Cocozza, A., Dacre, H. F., Feng, Y., Fraedrich, K., Grieger, J., Gulev, S., Hanley, J., Hewson, T., Inatsu, M., Keay, K., Kew, S. F., Kindem, I., Leckebusch, G. C., Liberato, M. L. R., Lionello, P., Mokhov, I. I., Pinto, J. G., Raible, C. C., Reale, M., Rudeva, I., Schuster, M., Simmonds, S., Sinclair, M., Sprenger, M., Tilinina, N. D., Trigo, I. F., Ulbrich, S., Ulbrich, U., L. Wang, X. L., and Wernli, H.: IMILAST - A Community Effort to Intercompare Extratropical Cyclone Detection and Tracking Algorithms, B. Am. Meteorol. Soc., 94, 529-547, https://doi.org/10.1175/BAMS-D-11-00154.1, 2013.

Ogi, M., Yamazaki, K., and Wallace, J. M.: Influence of winter and summer surface wind anomalies on summer Arctic sea ice extent, Geophys. Res. Lett., 37, L07701, https://doi.org/10.1029/2009GL042356, 2010.

Onogi, K., Junichi Tsutsui, J., Koide, H., Sakamoto, M., Kobayashi, S., Hatsushika, H., Matsumoto, T., Yamazaki, N., Kamahori, H., Takahashi, K., Kadokura, S., Wada, K., Kato, K., Oyama, R., Ose, T., Mannoji, N., and Taira, R.: The JRA-25 Reanalysis, J. Meteorol. Soc. Jpn., 85, 369-432, https://doi.org/10.2151/jmsj.85.369, 2007.

Parkinson, C. L. and Comiso, J. C.: On the 2012 record low Arctic sea ice cover: Combined impact of preconditioning and an August storm, Geophys. Res. Lett., 40, 1356-1361, https://doi.org/10.1002/grl.50349, 2013. 
Rae, J. G. L., Hewitt, H. T., Keen, A. B., Ridley, J. K., West, A. E., Harris, C. M., Hunke, E. C., and Walters, D. N.: Development of the Global Sea Ice 6.0 CICE configuration for the Met Office Global Coupled model, Geosci. Model Dev., 8, 2221-2230, https://doi.org/10.5194/gmd-8-2221-2015, 2015.

Raible, C. C., Della-Marta, P. M., Schwierz, C., Wernli, H., and Blender, R.: Northern Hemisphere extratropical cyclones: A comparison of detection and tracking methods and different reanalyses, Mon. Weather Rev., 136, 880-897, https://doi.org/10.1175/2007MWR2143.1, 2008.

Rayner, N. A., Parker, D. E., Horton, E. B., Folland, C. K., Alexander, L. V., Rowell, D. P., Kent, E. C., and Kaplan, A.: Global analyses of sea surface temperature, sea ice, and night marine air temperature since the late nineteenth century, J. Geophys. Res., 108, 4407, https://doi.org/10.1029/2002JD002670, 2003.

Rienecker, M. M., Suarez, M. J., Gelaro, R., Todling, R., Bacmeister, J., Liu, E., Bosilovich, M. G., Schubert, S. D., Takacs, L., Kim, G.-K., Bloom, S., Chen, J., Collins, D., Conaty, A., da Silva, A., Gu, W., Joiner, J., Koster, R. D., Lucchesi, R., Molod, A., Owens, T., Pawson, S., Pegion, P., Redder, C. R., Reichle, R., Robertson, F. R., Ruddick, A. G., Sienkiewicz, M., and Woollen, J.: MERRA: NASA's Modern-Era Retrospective Analysis for Research and Applications, J. Climate, 24, 3624-3648, https://doi.org/10.1175/JCLI-D-11-00015.1, 2011.

Rudeva, I., Gulev, S. K., Simmonds, I., and Tilinina, N.: The sensitivity of characteristics of cyclone activity to identification procedures in tracking algorithms, Tellus A, 66, 24961, https://doi.org/10.3402/tellusa.v66.24961, 2014.

Screen, J. A. and Simmonds, I.: Erroneous Arctic Temperature Trends in the ERA-40 Reanalysis: A Closer Look, J. Climate, 24, 2620-2627, https://doi.org/10.1175/2010JCLI4054.1, 2011.

Screen, J. A., Simmonds, I., and Keay, K.: Dramatic interannual changes of perennial Arctic sea ice linked to abnormal summer storm activity, J. Geophys. Res., 116, D15105, https://doi.org/10.1029/2011JD015847, 2011.

Semtner, A. J.: A model for the thermodynamic growth of sea ice in numerical investigations of climate, J. Phys. Oceanog., 6, 379389, 1976.

Simmonds, I. and Keay, K.: Extraordinary September Arctic sea ice reductions and their relationships with storm behavior over 1979-2008, Geophys. Res. Lett., 36, L19715, https://doi.org/10.1029/2009GL039810, 2009.

Simmonds, I. and Rudeva, I.: The great Arctic cyclone of August 2012, Geophys. Res. Lett., 39, L23709, https://doi.org/10.1029/2012GL054259, 2012.

Simmonds, I., Keay, K., and Lim, E. P.: Synoptic activity in the seas around Antarctica, Mon. Weather Rev., 131, 272-288, https://doi.org/10.1175/15200493(2003)131<0272:SAITSA>2.0.CO;2, 2003.
Titchner, H. A. and Rayner, N. A.: The Met Office Hadley Centre sea ice and sea surface temperature data set, version 2: 1 . Sea ice concentrations, J. Geophys. Res.-Atmos., 119, 2864-2889, https://doi.org/10.1002/2013JD020316, 2014.

Valcke, S.: The OASIS3 coupler: a European climate modelling community software, Geosci. Model Dev., 6, 373-388, https://doi.org/10.5194/gmd-6-373-2013, 2013.

Vaughan, D. G., Comiso, J. C., Allison, I., Carrasco, J., Kaser, G., Kwok, R., Mote, P., Murray, T., Paul, F., Ren, J., Rignot, E., Solomina, O., K., S., and Zhang, T.: Observations: Cryosphere, in: Climate Change 2013: The Physical Science Basis, Contribution of Working Group I to the Fifth Assessment Report of the Intergovernmental Panel on Climate Change, edited by: Stocker, T. F., Qin, D., Plattner, G.-K., Tignor, M., Allen, S. K., Boschung, J., Nauels, A., Xia, Y., Bex, V., and Midgley, P. M., Cambridge University Press, Cambridge, UK, New York, NY, USA, 2013.

Walters, D., Boutle, I., Brooks, M., Melvin, T., Stratton, R., Vosper, S., Wells, H., Williams, K., Wood, N., Allen, T., Bushell, A., Copsey, D., Earnshaw, P., Edwards, J., Gross, M., Hardiman, S., Harris, C., Heming, J., Klingaman, N., Levine, R., Manners, J., Martin, G., Milton, S., Mittermaier, M., Morcrette, C., Riddick, T., Roberts, M., Sanchez, C., Selwood, P., Stirling, A., Smith, C., Suri, D., Tennant, W., Vidale, P. L., Wilkinson, J., Willett, M., Woolnough, S., and Xavier, P.: The Met Office Unified Model Global Atmosphere 6.0/6.1 and JULES Global Land 6.0/6.1 configurations, Geosci. Model Dev., 10, 14871520, https://doi.org/10.5194/gmd-10-1487-2017, 2017.

Williams, K. D., Harris, C. M., Bodas-Salcedo, A., Camp, J., Comer, R. E., Copsey, D., Fereday, D., Graham, T., Hill, R., Hinton, T., Hyder, P., Ineson, S., Masato, G., Milton, S. F., Roberts, M. J., Rowell, D. P., Sanchez, C., Shelly, A., Sinha, B., Walters, D. N., West, A., Woollings, T., and Xavier, P. K.: The Met Office Global Coupled model 2.0 (GC2) configuration, Geosci. Model Dev., 8, 1509-1524, https://doi.org/10.5194/gmd-8-15092015, 2015.

Woodgate, R. A., Weingartner, T., and Lindsay, R.: The 2007 Bering Strait oceanic heat flux and anomalous Arctic sea-ice retreat, Geophys. Res. Lett., 37, L01602, https://doi.org/10.1029/2009GL041621, 2010.

Zhang, J., Lindsay, R., Steele, M., and Schweiger, A.: What drove the dramatic retreat of arctic sea ice during summer 2007?, Geophys. Res. Lett., 35, L11505, https://doi.org/10.1029/2008GL034005, 2008.

Zhang, J., Lindsay, R., Schweiger, A., and Steele, M.: The impact of an intense summer cyclone on 2012 Arctic sea ice retreat, Geophys. Res. Lett., 40, 720-726, https://doi.org/10.1002/grl.50190, 2013. 